\title{
Experimental Model of Zymosan-Induced Arthritis in the Rat Temporomandibular Joint: Role of Nitric Oxide and Neutrophils
}

\author{
Hellíada Vasconcelos Chaves, ${ }^{1,2}$ Ronaldo de Albuquerque Ribeiro, ${ }^{3}$ \\ André Mattos Brito de Souza, ${ }^{3}$ Antonio Alfredo Rodrigues e Silva, ${ }^{1}$ Antoniella Souza Gomes, ${ }^{3}$ \\ Mariana Lima Vale, ${ }^{3}$ Mirna Marques Bezerra, ${ }^{2}$ and Gerly Anne de Castro Brito ${ }^{4}$ \\ ${ }^{1}$ Faculty of Dentistry, Federal University of Ceará, Sobral Campus, Avenida Comandante Maurocélio Rocha Pontes, 100 Derby, \\ 62042-280 Sobral, CE, Brazil \\ ${ }^{2}$ Faculty of Medicine of Sobral, Federal University of Ceará, Sobral Campus, Avenida Comandante Maurocélio Rocha Pontes, \\ 100 Derby, 62042-280 Sobral, CE, Brazil \\ ${ }^{3}$ Department of Physiology and Pharmacology, Faculty of Medicine, Federal University of Ceará, Rua Coronel Nunes Valente, \\ 1315 Rodolfo Teófilo, 60430-270 Fortaleza, CE, Brazil \\ ${ }^{4}$ Department of Morphology, Faculty of Medicine, Federal University of Ceará, Rua Delmiro de Farias, Porangabussu, \\ 60440-261 Fortaleza, CE, Brazil
}

Correspondence should be addressed to Hellíada Vasconcelos Chaves, helliadachaves@yahoo.com.br

Received 15 September 2010; Revised 2 December 2010; Accepted 9 December 2010

Academic Editor: Oreste Gualillo

Copyright ( $) 2011$ Hellíada Vasconcelos Chaves et al. This is an open access article distributed under the Creative Commons Attribution License, which permits unrestricted use, distribution, and reproduction in any medium, provided the original work is properly cited.

\begin{abstract}
Aims. To establish a new model of zymosan-induced temporomandibular joint (TMJ) arthritis in the rat and to investigate the role of nitric oxide. Methods. Inflammation was induced by an intra-articular injection of zymosan into the left TMJ. Mechanical hypernociception, cell influx, vascular permeability, myeloperoxidase activity, nitrite levels, and histological changes were measured in TMJ lavages or tissues at selected time points. These parameters were also evaluated after treatment with the nitric oxide synthase (NOS) inhibitors L-NAME or 1400 W. Results. Zymosan-induced TMJ arthritis caused a time-dependent leucocyte migration, plasma extravasation, mechanical hypernociception, and neutrophil accumulation between 4 and $24 \mathrm{~h}$. TMJ immunohistochemical analyses showed increased inducible NOS expression. Treatment with L-NAME or $1400 \mathrm{~W}$ inhibited these parameters. Conclusion. Zymosan-induced TMJ arthritis is a reproducible model that may be used to assess both the mechanisms underlying TMJ inflammation and the potential tools for therapies. Nitric oxide may participate in the inflammatory temporomandibular dysfunction mechanisms.
\end{abstract}

\section{Introduction}

Temporomandibular joint (TMJ) disorders are a group of conditions that result in TMJ pain, which frequently limits talking, chewing, and other basic daily activities with high levels of pain-related disability [1]. Although these conditions may be measured in terms of lost productivity and human suffering, little is known about the underlying pathogenesis of temporomandibular disorder-related pain.

Experimental models that allow the study of the mechanisms underlying these inflammatory and pain conditions are of great clinical relevance. Rat models of TMJ inflammation have been developed using intra-articular injections of proinflammatory agents [2-17]. In this regard, zymosan, a polysaccharide from yeast cell walls, produces a severe and erosive synovitis $[18,19]$ associated with hyperalgesia in animal models of knee arthritis [20]. This model has been largely used in the study of knee arthritis, but to our knowledge, no study has used zymosan to induce TMJ arthritis.

Nitric oxide (NO) is synthesized by nitric oxide synthase (NOS) from L-arginine, and three isoforms of NOS have been described. The endothelial (NOS1) and neuronal 
(NOS3) isoforms are constitutive, whereas NOS2 is the inducible isoform (iNOS) [21]. The immunohistochemical localization of inducible NOS in the synovial tissue of human TMJs has been demonstrated previously [22]. In addition, an antinociceptive action of $\mathrm{NO}$ in the caudal part of the spinal trigeminal nucleus during chronic carrageenaninduced arthritis in rats TMJ has been described [23]. Despite this experimental evidence showing an involvement of NO in TMJ arthritis, the role of the L-arginine: $\mathrm{NO}$ system remains controversial. A striking therapeutic benefit with reduced signs and symptoms of erosive arthritis following the inhibition of NO production with nonspecific NOS inhibitors has been observed [24]. However, selective iNOS inhibition exacerbates synovial inflammation and joint degradation [25].

The aim of this study was to establish a new model of zymosan-induced TMJ arthritis in the rat. Considering that both the mediators involved in pain mechanisms during inflammatory arthropathies and the exact role of $\mathrm{NO}$ in pain development are still not fully defined, we also aimed to determine the time course of vascular and cellular events that occur secondarily to zymosan-induced TMJ arthritis in rats and the putative involvement of $\mathrm{NO}$ and neutrophils.

\section{Materials and Methods}

2.1. Animals. Male Wistar rats $(160-220 \mathrm{~g})$ were housed in standard plastic cages with food and water available ad libitum. They were maintained in a temperature-controlled room $\left(23 \pm 2^{\circ} \mathrm{C}\right)$ with a $12 / 12$-hour light-dark cycle. All experiments were designed to minimize animal suffering and to use the minimum number of animals required to achieve a valid statistical evaluation. This study was conducted in accordance with the Institutional Animal Care and Use Committee of the Federal University of Ceará.

2.2. Induction of TMJ Arthritis. Rats were anesthetized with tribromoethanol $(1 \mathrm{~mL} / 100 \mathrm{~g}$, i.p. $)$ and received an intraarticular (i.art.) injection of $0.25,0.5,1$, or $2 \mathrm{mg}$ zymosan ( $40 \mu \mathrm{L}$ total volume) dissolved in sterile saline into the left TMJ using a 30-gauge needle and $1-\mathrm{mL}$ syringe. Sham animals received saline i.art.

Before zymosan or saline injections, the TMJ skin region was carefully shaved, the posteroinferior border of the zygomatic arch was palpated, and the needle was inserted inferior to this point and advanced in a medial and anterior direction until the needle made contact with the condyle. This contact was verified by the moving of the mandible, and the puncture of the needle into the joint space was confirmed by the loss of resistance. Gentle aspiration ruled out intravascular placement, after which the specified volume of zymosan or saline was injected. To identify which dose of zymosan would be used, animals were sacrificed at $6 \mathrm{~h}$ after zymosaninduced arthritis and both nociceptive (facial nociceptive threshold) and inflammatory parameters (total cell counting and myeloperoxidase assay) were evaluated.

2.3. Evaluation of Mechanical Hypernociception. Mechanical hypernociception in the TMJ was evaluated by measuring the threshold of force intensity that needed to be applied to the TMJ region until the occurrence of a reflex response of the animal (e.g., head withdrawal). The measurements were performed by an examiner unaware of the treatments and used a digital device (Insight, Ribeirão Preto, SP, Brazil) that consisted of a rigid filament linked in an electronic device that measured the response threshold in grams (g) when the filament was applied to the surface of the tested region. The facial areas to be tested around the TMJ were carefully shaved, and the animals were put into individual plastic cages $45 \mathrm{~min}$ before the beginning of the tests. The animals were submitted to a conditioning session of head withdrawal threshold measurements in the testing room for 4 consecutive days under controlled temperatures $(23 \pm$ $2^{\circ} \mathrm{C}$ ) and low illumination. On the fifth day, the basal force threshold value was recorded (in triplicate) before the i.art. injections of either zymosan or vehicle and after $2 \mathrm{~h}, 4 \mathrm{~h}, 6 \mathrm{~h}$, $12 \mathrm{~h}, 24 \mathrm{~h}$, or $48 \mathrm{~h}$.

\subsection{Synovial Fluid Collection and Cell Counting. Zymosan} injection (i.art) was performed in anesthetized rats. At different time points after zymosan-injections $(2 \mathrm{~h}, 4 \mathrm{~h}, 6 \mathrm{~h}$, $12 \mathrm{~h}, 24 \mathrm{~h}$, or $48 \mathrm{~h}$ ), the rats were sacrificed under anesthesia and exsanguinated to analyze the responses at the required time points. The superficial tissues were dissected, and the TMJ cavity was washed to collect the synovial fluid (SF) by a pumping and aspiration technique using $0.5 \mathrm{~mL}$ of EDTA in neutral buffered PBS. This procedure was repeated twice. The total number of white cells in the synovial lavage fluid was counted using a Neubauer chamber.

2.5. Evans Blue Extravasation Measurement. Animals received an i.v. injection of Evans blue dye $(25 \mathrm{mg} / \mathrm{kg})$, dissolved in saline, $30 \mathrm{~min}$ before the times (e.g., $2 \mathrm{~h}, 4 \mathrm{~h}$, $6 \mathrm{~h}, 12 \mathrm{~h}, 24 \mathrm{~h}$, or $48 \mathrm{~h}$ ) after zymosan-induced arthritis. Immediately after the extraction, the tissue was weighed and placed in $2 \mathrm{~mL}$ of formaldehyde overnight. The supernatant $(100 \mu \mathrm{L})$ was extracted, and the absorbance at $630 \mathrm{~nm}$ was determined in spectrophotometer. The concentration was determined by comparison to a standard curve of known amounts of Evans blue dye in the extraction solution, which was assessed within the same assay. The amount of Evans blue dye $(\mu \mathrm{g})$ was then calculated per $\mathrm{mL}$ of exudate [26].

2.6. Myeloperoxidase Activity Analysis. Myeloperoxidase (MPO) is an enzyme found primarily in the azurophilic granules of the neutrophils and has been used extensively as a biochemical marker of granulocyte infiltration into various tissues. The MPO activity assay measurement has been described previously by bradley et al. [27]. In our study, the MPO assay was conducted on the collected synovial fluid and in TMJ tissues at different time points after zymosan injection ( $2 \mathrm{~h}, 4 \mathrm{~h}, 6 \mathrm{~h}, 12 \mathrm{~h}, 24 \mathrm{~h}$, or $48 \mathrm{~h}$ ). Briefly, 100-200 mg of TMJ tissue was homogenized in $1 \mathrm{~mL}$ of hexadecyltrimethylammonium bromide (HTAB) buffer for each $50 \mathrm{mg}$ of tissue. The homogenate was centrifuged at $4,500 \mathrm{rpm}$ for $12 \mathrm{~min}$ at $4^{\circ} \mathrm{C}$. MPO activity in the resuspended pellet was assayed by measuring the change in 
absorbance at $450 \mathrm{~nm}$ using o-dianisidine dihydrochloride and $1 \%$ hydrogen peroxide. The results are reported as the MPO units/joint fluid or unit/joint tissue. A unit of MPO activity was defined as the conversion of $1 \mu \mathrm{mol}$ of hydrogen peroxide to water in $1 \mathrm{~min}$ at $22^{\circ} \mathrm{C}$.

2.7. Determination of Nitric Oxide Production. The Griess reaction was used as an indirect assay of $\mathrm{NO}$ production and determined the total nitrite $\left(\mathrm{NO}_{2}\right)$ and nitrate $\left(\mathrm{NO}_{3}\right)$ as a measure of the degree of $\mathrm{NO}$ production. Total $\mathrm{NO}_{2}$ and $\mathrm{NO}_{3}$ levels were determined after conversion of $\mathrm{NO}_{3}$ in the synovial exudate supernatants $(0.08 \mathrm{~mL})$ to $\mathrm{NO}_{2}$ by incubation with $0.01 \mathrm{~mL}$ nitrate reductase from an Aspergillus species and $0.01 \mathrm{~mL} \mathrm{NADPH}(1 \mathrm{mM})$ for $30 \mathrm{~min}$ at $37^{\circ} \mathrm{C}$. The $\mathrm{NO}_{2}$ levels were determined spectrophotometrically at $540 \mathrm{~nm}$ by comparing the absorbance of a $0.1 \mathrm{~mL}$ sample after adding $0.1 \mathrm{~mL}$ Griess reagent (sulfanilic acid $\left(1 \% \mathrm{wv}^{-1}\right)$ and $\mathrm{N}-(1-$ naphythyl) ethylenediamine $\left(0.1 \mathrm{wv}^{-1}\right)$ in $5 \%$ phosphoric acid to a $\mathrm{NaNO}_{2}$ (1-100 mM) standard).

2.8. Histopathological Analysis. After sacrifice at $6 \mathrm{~h}$ after zymosan-induced arthritis, the TMJ was excised. The specimens were fixed in 10\% neutral buffered formalin for $24 \mathrm{~h}$, demineralized in 10\% EDTA, embedded in paraffin, and sectioned along the long axis of the TMJ. Sections of $5 \mu \mathrm{m}$, which included the condyle, articular cartilage, articular disc, synovial membrane, periarticular tissue, and the skeletal muscle periarticular tissue, were evaluated under light microscopy.

For the specimens processed for routine hematoxylineosin ( $\mathrm{H} \& \mathrm{E})$ staining, histological analysis considered a 0-4 score grade based on the following parameters: cell influx in the synovial membrane (SM), cell influx in the periarticular tissue and in the skeletal muscle periarticular tissue, and the thickness of synovial membrane.

2.9. Immunohistochemistry for iNOS. Immunohistochemistry for iNOS was performed using the streptavidin-biotinperoxidase method in formalin-fixed, paraffin-embedded tissue sections ( $5 \mu \mathrm{m}$ thick), mounted on poly-L-lysinecoated microscope slides. The sections were deparaffinized and rehydrated through xylene and a graded series of alcohols. After antigen retrieval, endogenous peroxidase was blocked $(15 \mathrm{~min})$ with $3 \%(\mathrm{v} / \mathrm{v})$ hydrogen peroxide, and the sections were washed in phosphate-buffered saline (PBS). Sections were incubated overnight $\left(4^{\circ} \mathrm{C}\right)$ with a primary rabbit anti-iNOS antibody diluted 1:100 in PBS plus bovine serum albumin (PBS-BSA). The slides were then incubated with a biotinylated goat antirabbit antibody diluted 1:400 in PBS-BSA. After washing, the slides were incubated with an avidin-biotin-horseradish peroxidase conjugate (Strep ABC complex, Vectastain ABC Reagent and peroxidase substrate solution) for $30 \mathrm{~min}$ according to the Vectastain protocol. iNOS was visualized with the chromogen 3,3'diaminobenzidine (DAB). Negative control sections were processed simultaneously as described above but with the first antibody being replaced by $5 \%$ PBS-BSA.
None of the negative controls showed iNOS immunoreactivity. Slides were counterstained with Harry's hematoxylin, dehydrated in a graded alcohol series, cleared in xylene, and coverslipped.

2.10. Treatment. The NO inhibitors, L-NG-nitroarginine methyl ester (L-NAME) (10, 30, or $100 \mathrm{mg} / \mathrm{kg}$, i.p.), which is a nonselective NOS inhibitor, and $\mathrm{N}$-[[3(aminomethyl)phenyl]methyl]-ethanimidamide (1400 W) ( 0.5 or $1 \mathrm{mg} / \mathrm{kg}$, s.c.), which is a selective iNOS inhibitor, were used $30 \mathrm{~min}$ before zymosan-induced arthritis. Indomethacin $(5 \mathrm{mg} / \mathrm{kg}$, s.c.) was used as a positive control $1 \mathrm{~h}$ before zymosan injection.

2.11. Statistical Analysis. The data are presented as the means \pm S.E.M. or medians, where appropriate. Differences between means were compared using a one-way ANOVA followed by the Bonferroni test. The Kruskal-Wallis test followed by Dunn's test was used to compare medians. A probability value of $P<.05$ indicated significant differences.

\section{Results}

3.1. Dose Response and Time Course of Zymosan-Induced TMJ Inflammation and Mechanical Hypernociception. The dose response of zymosan-induced TMJ arthritis was first standardized and validated and was followed by a temporal profile assessment. Zymosan at $2 \mathrm{mg}$ was chosen, instead of $0.25,0.5$, or $1 \mathrm{mg}$, because this dose was the only one that changed both the nociceptive behavior and the inflammatory parameters.

Mechanical hypernociception induced by zymosan started at $2 \mathrm{~h}$ at all of the doses tested, although zymosan at $2 \mathrm{mg}$ showed a significant reduction in mechanical threshold during the 4th and 6th h compared to $0.25,0.5$, or $1 \mathrm{mg}$ (Figure 1(a)). Furthermore, zymosan at $2 \mathrm{mg}$ significantly increased $(P<.05)$ the leukocyte count in the synovial fluid (Figure 1(b)), MPO activity in the TMJ fluid (Figure 1(c)), and MPO activity in the TMJ tissue (Figure $1(\mathrm{~d})$ ) at the 6 th $\mathrm{h}$ after the induction of TMJ arthritis compared to the other groups (Figures 1(b), 1(c), and 1(d)).

The intra-articular (i.art.) 2-mg injection of zymosan resulted in a time-dependent mechanical hypernociception as measured by a clear decrease in the mechanical threshold for head withdrawal (Figure 2(a)). This zymosan-induced mechanical hypernociception started at the 2-hour time point $(P<.05$ versus Sham), peaked between $4 \mathrm{~h}$ and $6 \mathrm{~h}$ $(P<.05$ versus Sham $)$, and lasted for up to $24 \mathrm{~h}(P<.05$ versus Sham). In the intra-articular saline-injected animals (Sham), no significant changes in mechanical withdrawal thresholds were observed at any time point.

A 2-mg injection of zymosan resulted in a significant increase in the number of polymorphonuclear cells. The total leukocyte count showed that during the 4 th h, an influx of leukocytes was initiated. The influx of leukocytes peaked during the 6 th $\mathrm{h}$ and was maintained until the 12 th $\mathrm{h}$ (Figure $2(\mathrm{~b}))(P<.05$ versus Sham). This increase in neutrophils was certified by the increase of MPO activity 


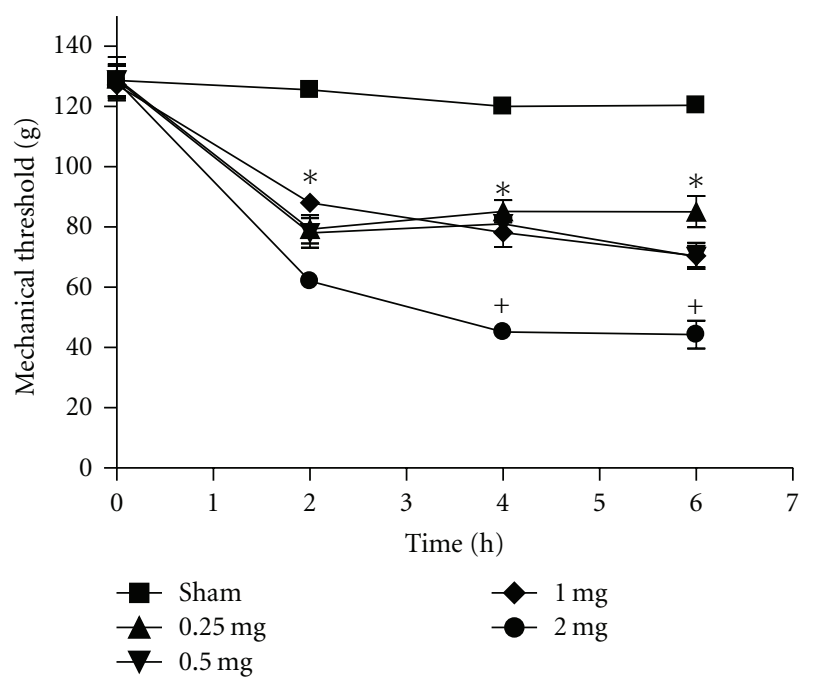

(a)

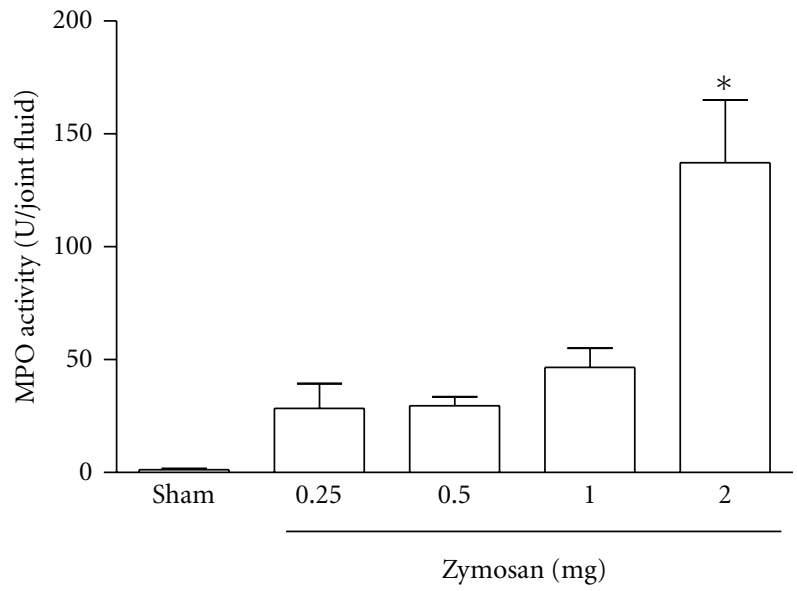

(c)

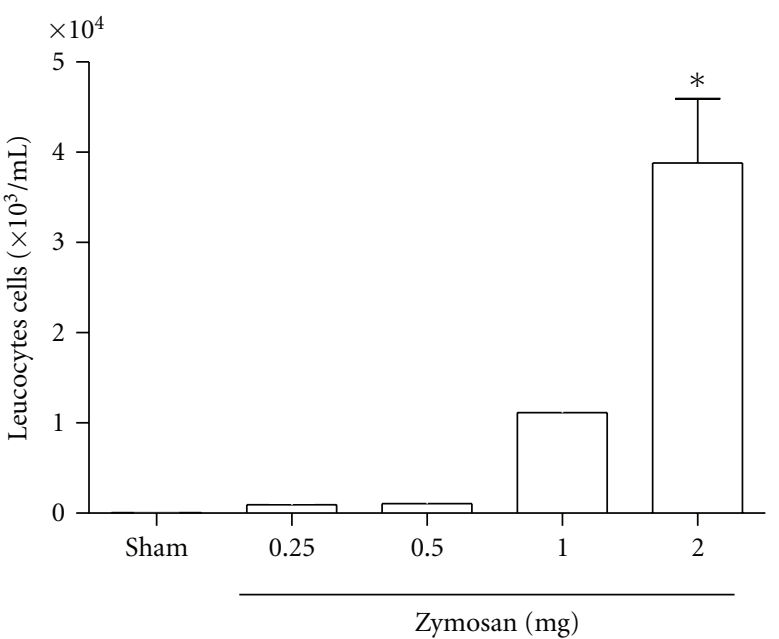

(b)

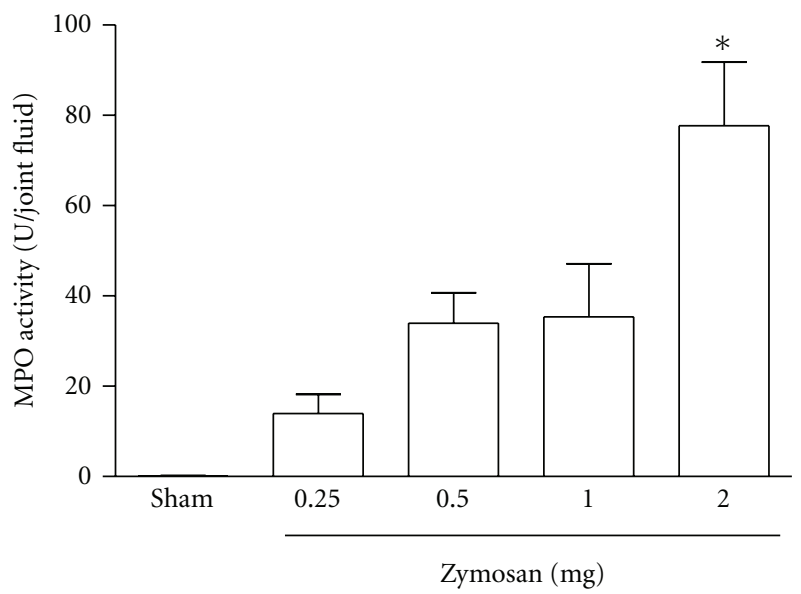

(d)

FIGURE 1: Inflammatory and hypernociceptive dose-response effect of zymosan-induced TMJ arthritis. Zymosan $(0.25,0.5,1$, or 2 mg; $40 \mu \mathrm{L})$ or saline was injected i.art. into the left TMJ of the rat. The mechanical nociceptive threshold was measured before and after an i.art. injection of zymosan or saline for 6 hours (a). Leukocyte migration was evaluated by cell counting in TMJ fluid (b). MPO activity was evaluated in TMJ fluid (c) and TMJ tissues (d) for $6 \mathrm{~h}$ after an i.art. injection of zymosan or saline. Data are expressed as means \pm SEM $(n=6) .{ }^{*} P<.05$ versus Sham. ${ }^{+} P<.05$ versus $0.25,0.5$, and $1 \mathrm{mg}$ groups (ANOVA, Bonferroni).

both from the synovial lavage fluid (Figure 2(c)) and the TMJ tissue (Figure $2(\mathrm{~d}))(P<.05$ versus Sham). MPO is an enzyme found primarily in the azurophilic granules of neutrophils. These changes were accompanied by plasma extravasation that occurred in the TMJ during both the 4th and 6th h (Figure 2(e)) and peaked again at the 24th $\mathrm{h}$ $(P<.05$ versus Sham $)$. The second phase of Evans blue dye extravasation at $24 \mathrm{~h}$, which was not accompanied by MPO activity, may be related to an endothelial barrier disruption as described previously [28], but this hypothesis deserves further investigation.

During the time course of zymosan TMJ arthritis development, hypernociception was maximal at $4 \mathrm{~h}$ of arthritis, whereas cell influx peaked at $6 \mathrm{~h}$. Based on these results, we used these time points to assess the mechanisms underlying TMJ inflammation and hypernociception.
3.2. Histopathological Analysis. In the 6th h after zymosaninduced TMJ arthritis, an inflammatory cell influx was observed in the synovial membrane, the periarticular tissue, the musculoskeletal tissue, and the thickness in synovial membrane (Figures 3(b) and 3(c)) compared to the Sham group (Figure 3(a)). The cell types were predominantly neutrophils, which characterized acute inflammation. Edema was also observed in the synovium (Figure 3(c)). Table 1 shows the scores attributed to TMJ's histopathological analysis and compares the values between the Sham and zymosan arthritic TMJ groups. A significant $(P<.05)$ increase in the inflammatory parameters was observed in the zymosan group.

3.3. Effects of L-NAME and $1400 \mathrm{~W}$. L-NAME $(100 \mathrm{mg} / \mathrm{kg})$ and $1400 \mathrm{~W}(1 \mathrm{mg} / \mathrm{kg})$ significantly reduced the mechanical 

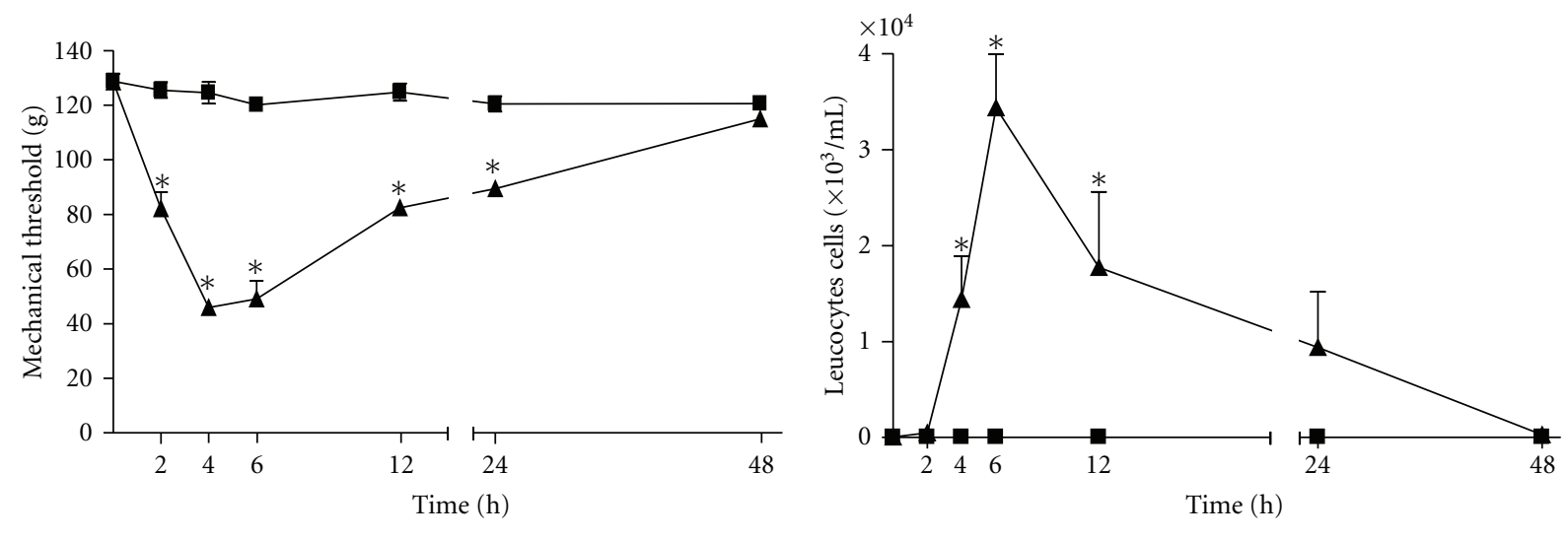

- Sham
- Zymosan $2 \mathrm{mg}$

- Sham
$-\leftarrow$ Zymosan $2 \mathrm{mg}$

(a)

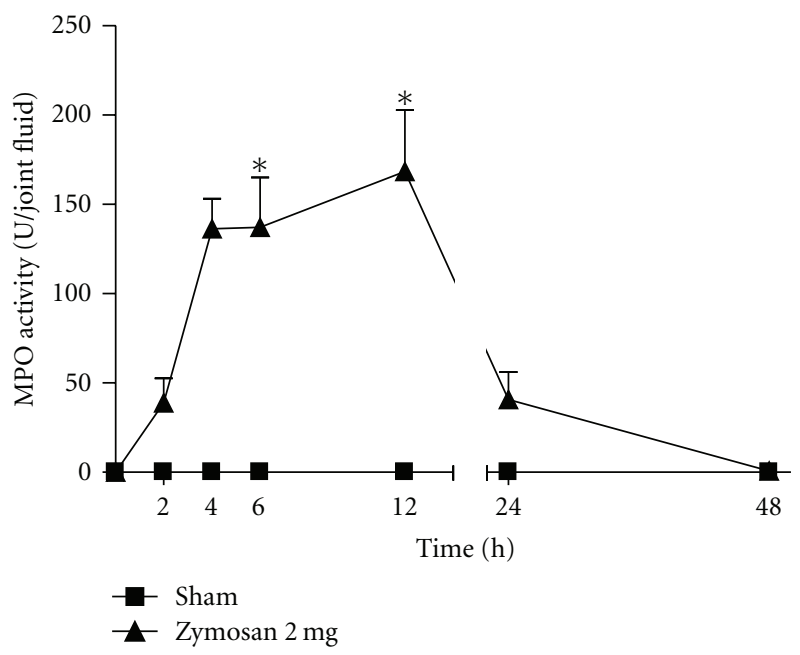

(c)

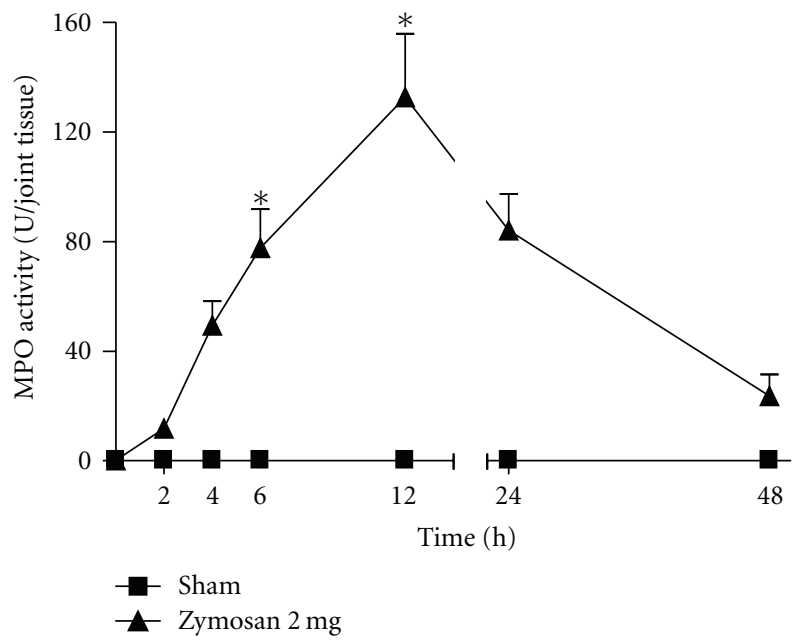

(d)

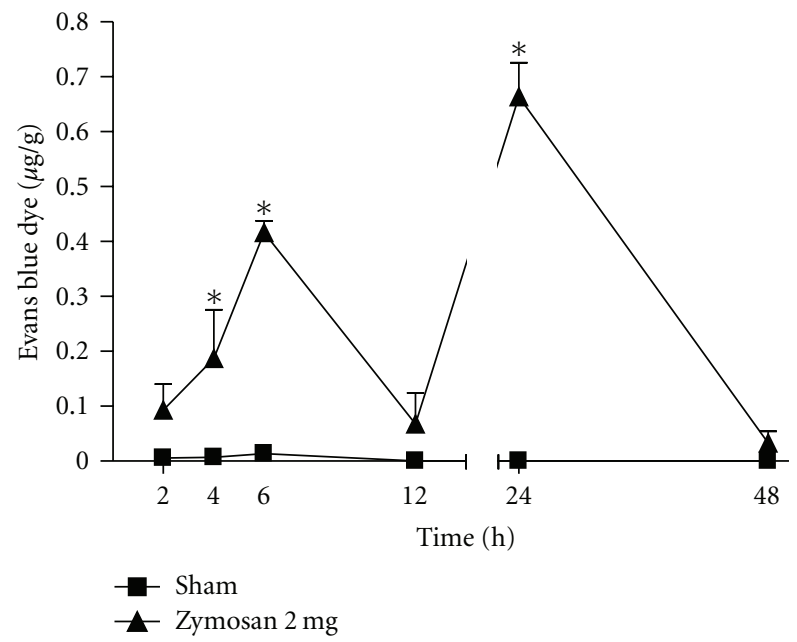

(e)

FIGURE 2: Temporal profile $(0-48 \mathrm{~h})$ of the inflammatory and hypernociceptive effects of zymosan-induced TMJ arthritis. Zymosan (2 mg; $40 \mu \mathrm{L}$ ) or saline was injected i.art. into the left TMJ of the rat. The mechanical nociceptive threshold was measured before and after an i.art. injection of zymosan or saline until the 48th hour (a). Leukocyte migration was evaluated by cell counting in TMJ fluid (b). MPO activity from TMJ fluid (c) and TMJ tissues (d). Plasma extravasation (PE) following an i.art. injection of zymosan or saline (e). Data are expressed as means $\pm \operatorname{SEM}(n=6) .{ }^{*} P<.05$ versus Sham (ANOVA, Bonferroni). 


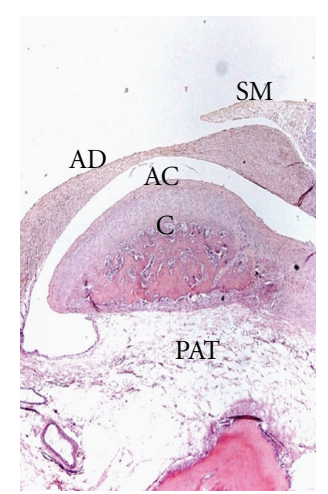

(a)

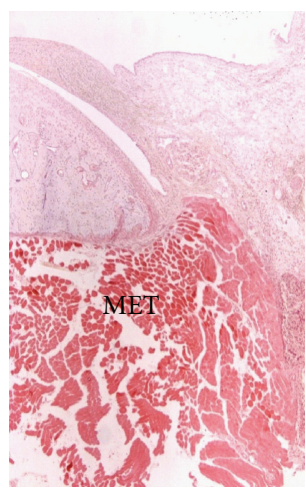

(b)

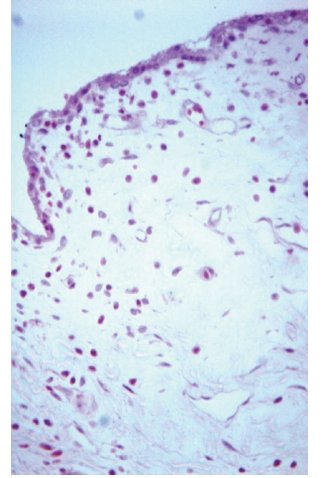

(c)

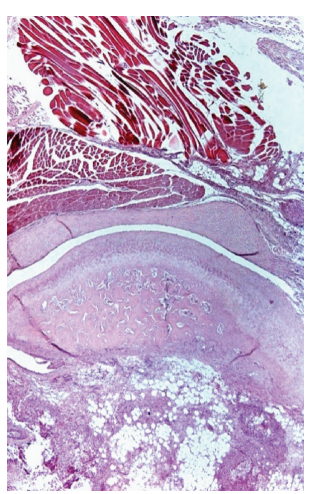

(d)

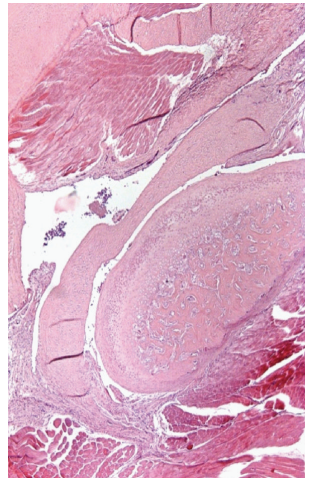

(e)

FIGURE 3: Photomicrographs of the histopathological analysis of TMJ and periarticular tissues. Photomicrographs of TMJ and periarticular tissues of nontreated (a, b, c) and L-NAME $100 \mathrm{mg} / \mathrm{kg}$ or $1400 \mathrm{~W} 1 \mathrm{mg} / \mathrm{kg}$ treated animals (d, e). (a) Normal group TMJ (40x). (b) Arthritic rats, TMJ induced by zymosan $2 \mathrm{mg}(40 \mathrm{x})$ showing inflammatory cell influx in the synovial membrane, periarticular tissue, musculoskeletal tissue, and synovial membrane thickness. (c) Synovial tissue of arthritic rats injected with zymosan 2 mg (400x) showing edema and inflammatory cell influx with polymorphonuclear predominance. (d) TMJ of arthritic rats injected with zymosan 2 mg and treated with L-NAME $100 \mathrm{mg} / \mathrm{kg}$ (40x). (e) TMJ of arthritic rats injected with zymosan $2 \mathrm{mg}$ treated with $1400 \mathrm{~W} 1 \mathrm{mg} / \mathrm{kg}$ (40x). C: condyle; AC: articular cartilage; AD: articular disc; SM: synovial membrane; PAT: periarticular tissue; MET: musculoskeletal tissue. Hematoxylin and eosin staining.

TABLE 1: Histopathological analysis of TMJ: the effects of nitric oxide synthase (NOS) inhibitors.

\begin{tabular}{lcccc}
\hline & $\begin{array}{c}\text { Cell influx in the } \\
\text { synovial membrane }\end{array}$ & $\begin{array}{c}\text { Synovial membrane } \\
\text { thickness }\end{array}$ & Periarticular cell influx & $\begin{array}{c}\text { Cell influx in the } \\
\text { muscular tissue }\end{array}$ \\
\hline Sham & $0(0-0)$ & $0(0-0)$ & $0(0-0)$ & $0(0-0)$ \\
Zymosan & $2.5(1-3)^{*}$ & $3(0-3)^{*}$ & $4(4-4)^{*}$ & $3(2-4)^{*}$ \\
\hline L-NAME $100 \mathrm{mg} / \mathrm{kg}$ & $0.5(0-1)^{+}$ & $0(0-0)^{+}$ & $1(0-2)^{+}$ & $0(0-0)^{+}$ \\
\hline $1400 \mathrm{~W} 1 \mathrm{mg} / \mathrm{kg}$ & $0(0-0)^{+}$ & $0(0-0)^{+}$ & $1(0-2)^{+}$ & $0(0-0)^{+}$ \\
\hline$* P<.05$ verus Sham ${ }^{+} P<.05$ verus zymosan (Kruskal-Wallis, Dunn's)
\end{tabular}

${ }^{*} P<.05$ versus Sham. ${ }^{+} P<.05$ versus zymosan (Kruskal-Wallis, Dunn's).

nociceptive thresholds (Figures $4(\mathrm{a})$ and $4(\mathrm{~b})$ ) during the 4th h after zymosan-induced TMJ arthritis $(P<.05$ versus zymosan) and the leukocyte count (Figures $4(\mathrm{c})$ and 4(d)), MPO activity (Figures 4(e) and 4(f)), and plasma extravasation (Figure $4(\mathrm{~g})$ ) during the 6 th $\mathrm{h}$ after zymosaninduced TMJ arthritis $(P<.05$ versus zymosan). The antinociceptive effects of indomethacin were similar to those of L-NAME and the highest dose of $1400 \mathrm{~W}$ treatment. Interestingly, the same results were observed when the cellular influx was assessed in joint fluids. These results showed that the administration of both NO blockers and indomethacin inhibited nociception and inflammation in zymosan TMJ arthritis, suggesting an involvement of multiple mechanisms in zymosan-induced arthritis.

The histopathological analyses showed that L-NAME $(100 \mathrm{mg} / \mathrm{kg}$ ) (see Figure $3(\mathrm{~d})$ ) and $1400 \mathrm{~W}(1 \mathrm{mg} / \mathrm{kg}$ ) (see Figure $3(\mathrm{e})$ ) reduced the inflammatory parameters to a normal status with a lower inflammatory cell influx in the synovial membrane, the periarticular tissue, the musculoskeletal tissue, and a lower thickness in the synovial membrane. Table 1 shows the scores attributed to TMJ's histopathological analysis and compares the values between the zymosan arthritic TMJ group, L-NAME $(100 \mathrm{mg} / \mathrm{kg})$, and $1400 \mathrm{~W}(1 \mathrm{mg} / \mathrm{kg})$ groups. A significant $(P<.05)$ reduction in the inflammatory parameters was observed.
3.4. Immunohistochemical Analysis and Nitrite Levels in Synovial Exudates. An immunohistochemical analysis for iNOS showed an increase in iNOS expression, which was characterized by brown-colored cells in arthritic TMJ rats injected with zymosan (Figure 5(c)) compared to normal animals (Figure 5(b)), which exhibited only a light expression of iNOS. The cell types that expressed iNOS were the articular disc, articular cartilage chondrocytes, and synovial cells. The negative control group sections were composed of arthritic TMJ rats injected with zymosan that were not treated with an anti-iNOS antibody (Figure 5(a)).

The amount of nitrite/nitrate detected in the joint exudates, measured at the 6-hour time point after zymosan ( $2 \mathrm{mg}$, i.art.) administration, is shown in Figure 6. In rats whose joints were injected only with saline (Sham), the nitrite concentrations in the joint exudates were low and remained at these levels throughout the experimental period.

\section{Discussion}

Experimental animal models of TMJ arthritis have been proposed to study inflammation and pain conditions. Some authors have suggested the induction of TMJ arthritis surgically [29-32] or mechanically [33], using a systemic 


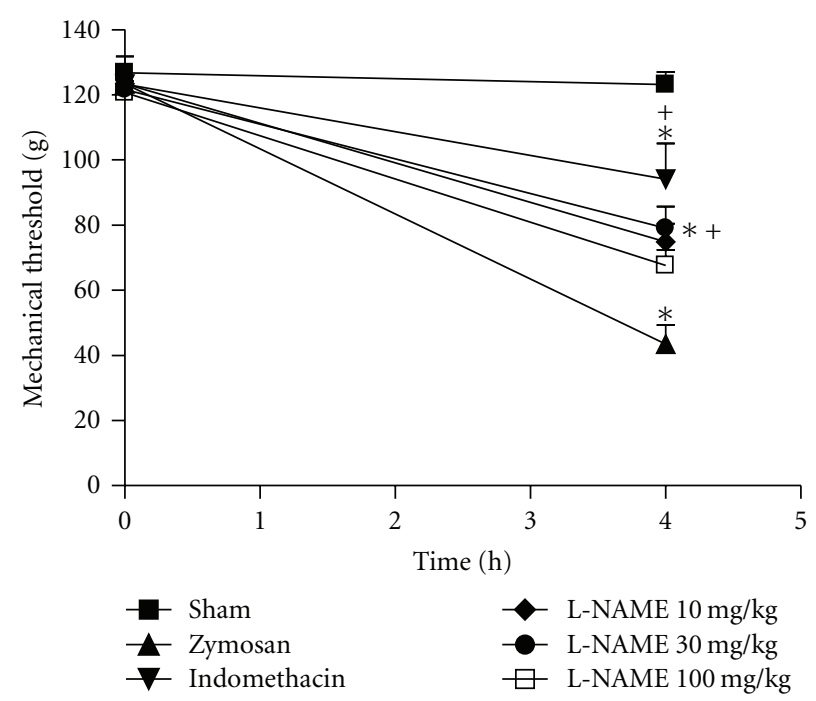

(a)

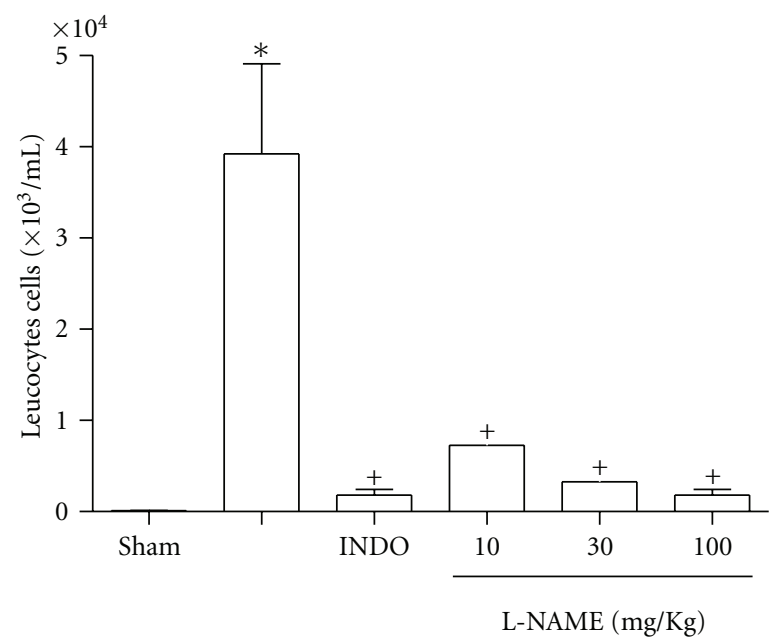

Zymosan $2 \mathrm{mg}$

(c)

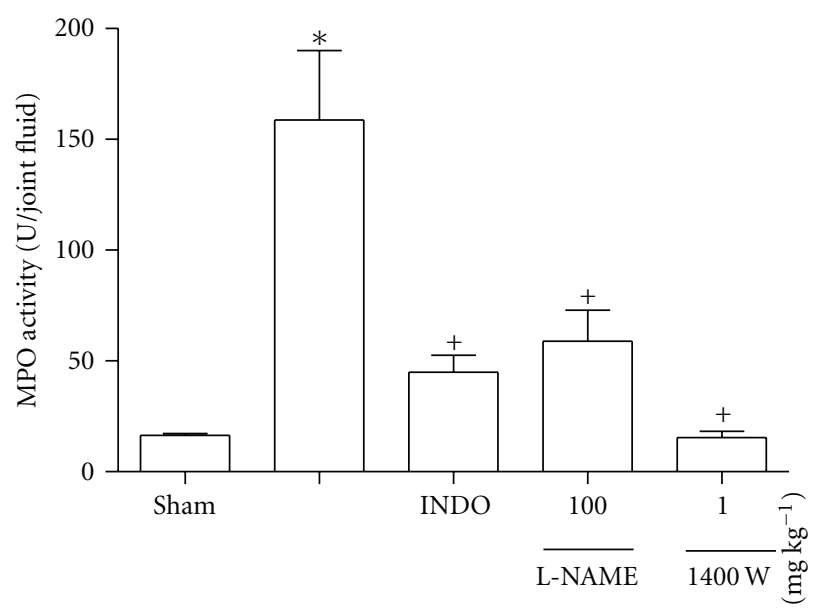

Zymosan $2 \mathrm{mg}$

(e)

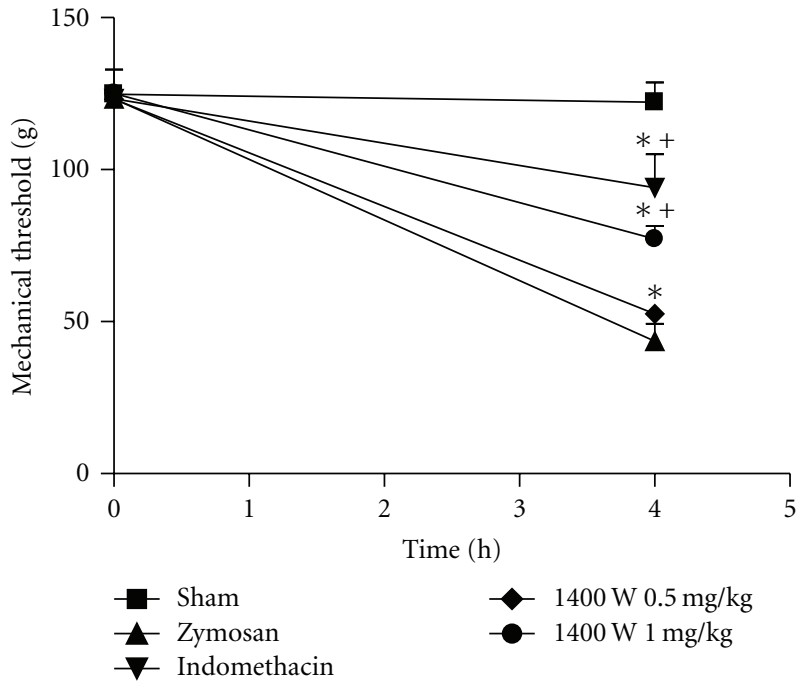

(b)

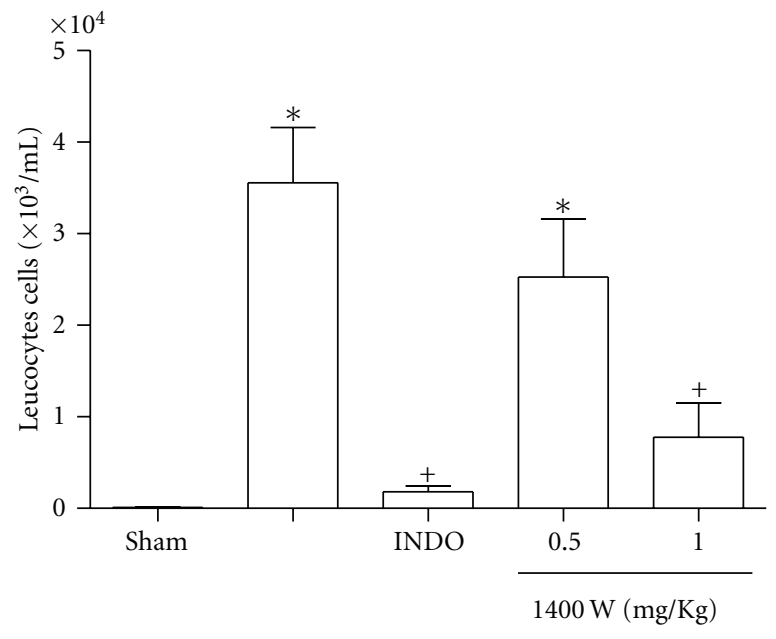

Zymosan $2 \mathrm{mg}$

(d)

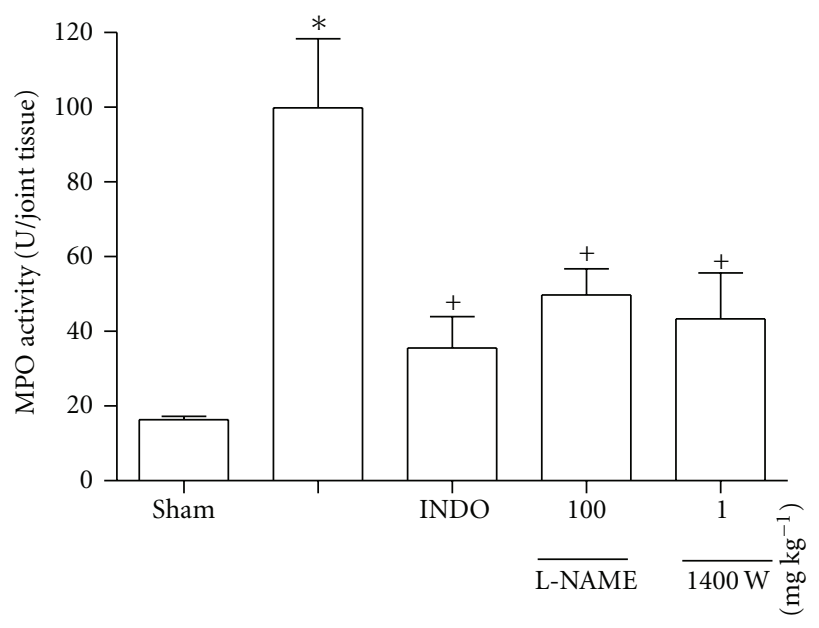

Zymosan 2 mg

(f)

Figure 4: Continued. 


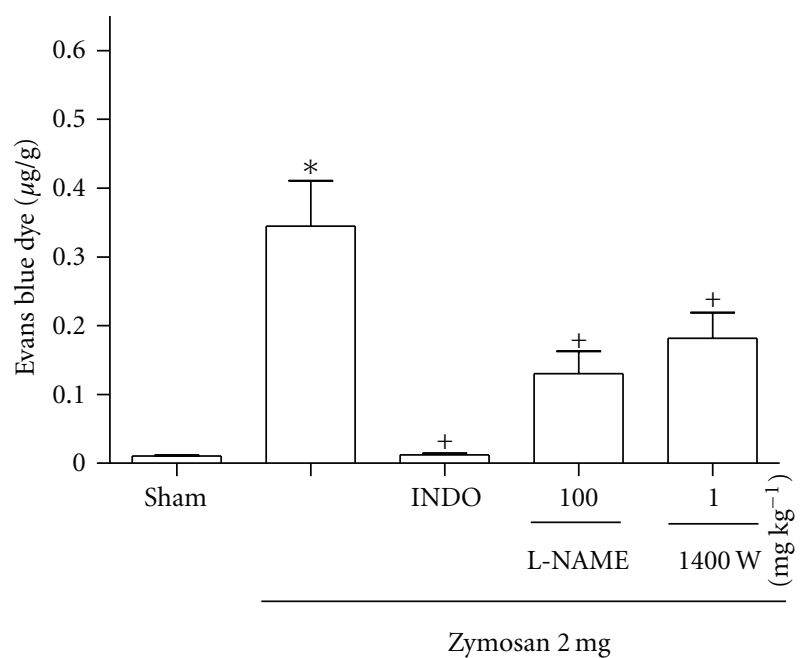

(g)

Figure 4: Effect of L-NAME and $1400 \mathrm{~W}$ on the inflammatory and hypernociceptive effects of zymosan in TMJ. Zymosan (2 mg; $40 \mu \mathrm{L})$ or saline was injected i.art. into the left TMJ of the rat. L-NAME $(100 \mathrm{mg} / \mathrm{kg})$ or $1400 \mathrm{~W}(1 \mathrm{mg} / \mathrm{kg})$ was injected (i.p.) $30 \mathrm{~min}$ before zymosan. The mechanical nociceptive threshold was measured in L-NAME- (a) and $1400 \mathrm{~W}$-treated (b) animals before and $4 \mathrm{~h}$ after an i.art. injection of zymosan or saline. After $6 \mathrm{~h}$, leukocyte migration was evaluated in L-NAME- (c) and 1400W-treated (d) animals by cell counting in TMJ fluid. MPO activity from TMJ fluid in L-NAME- and $1400 \mathrm{~W}$-treated animals (e). MPO activity in TMJ tissues in L-NAME- and 1400Wtreated animals (f). Plasma extravasation following an i.art. injection of zymosan or saline in L-NAME- and $1400 \mathrm{~W}$-treated animals (g). Data are expressed as means $\pm \operatorname{SEM}(n=6) .{ }^{*} P<.05$ versus Sham. ${ }^{+} P<.05$ versus zymosan (ANOVA, Bonferroni).

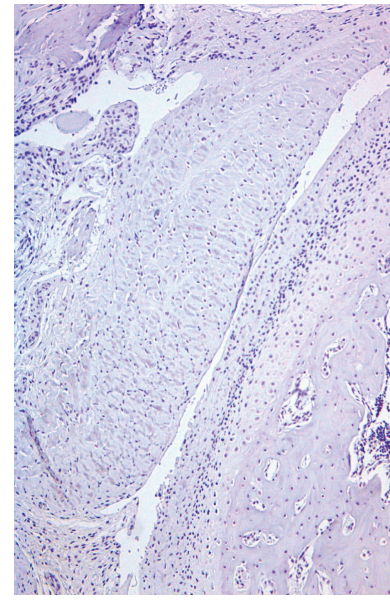

(a)

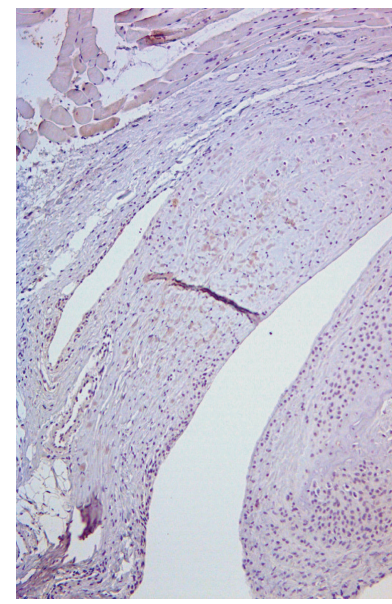

(b)

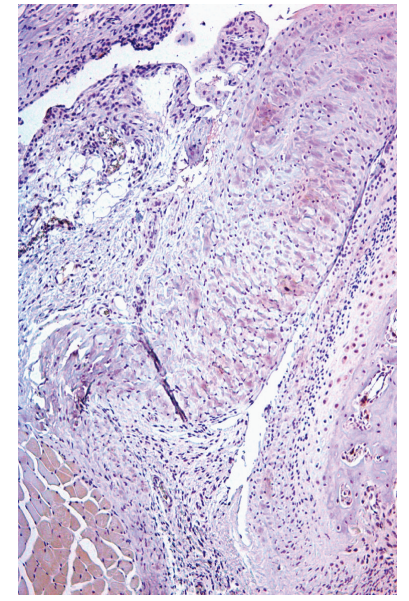

(c)

FIGURE 5: Photomicrographs of the immunostaining for iNOS in the TMJ and periarticular tissues of zymosan-induced TMJ arthritis in rats. (a) Negative control (sections in the absence of anti-iNOS antibody) of arthritic rats (100x). (b) Normal rat TMJ showing light immunostaining for iNOS (100x). (c) TMJ arthritis induced by zymosan 2 mg showing strong immunostaining for iNOS in chondrocytes and synoviocytes $(100 \mathrm{x})$.

injection of heat-inactivated group A Streptococcus pyogenes [34] or an injection in submandibular lymph nodes with Mycobacterium cells [35]. However, other models consisting of an intra-articular injection of inflammatory substances, such as $\mathrm{NaCI}, \mathrm{KCl}$, histamine [2], mustard oil [3, 4], substance P [5], heat-killed Mycobacterium butyricum in paraffin oil [6], human recombinant IL-1 $\alpha[7,8]$, glutamate [9], ovalbumin antigen [10], complete Freund's adjuvant
$[11,12]$, formalin [13], capsaicin [14], or carrageenan [1517], have been used previously.

Zymosan has been used as a pro-inflammatory agent for some time [36]. To our knowledge, this is the first demonstration of a zymosan-induced arthritis in the TMJ. Acute rat knee joint zymosan arthritis is characterized by an increase in vascular permeability, cell migration, and pain. Later, a progressive synovitis occurs with mononuclear cell 


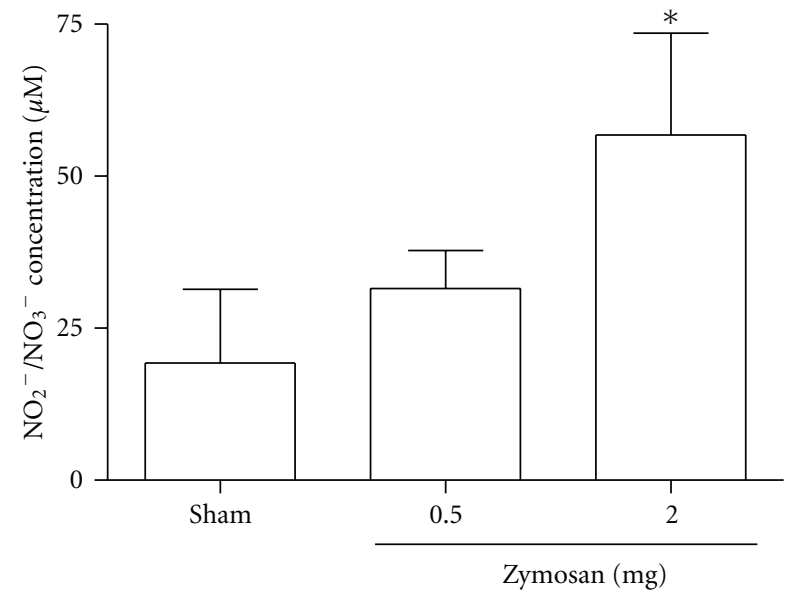

Figure 6: Nitrite levels in synovial exudates of zymosan-induced TMJ arthritis. Zymosan was injected i.art. and the NO release in exudates (as $\mathrm{NO}_{2}{ }^{-} / \mathrm{NO}_{3}{ }^{-}$) was measured $6 \mathrm{~h}$ after zymosan. Sham animals received only saline i.art. Injection of saline into the joints did not increase NO release throughout the experiment. Data are expressed as means $\pm \operatorname{SEM}(n=6) .{ }^{*} P<.05$ versus Sham (ANOVA, Bonferroni).

infiltration and a fibroblast reaction [18-20]. Our group has also demonstrated articular cartilage and subchondral bone degradation during the chronic stages of zymosan arthritis in the rat knee joint [24].

A zymosan 2-mg, but not saline, injection into the TMJ induced hypernociception, leukocyte influx, high MPO activity, and Evans blue dye extravasation, which was similar to the effects of zymosan rat knee joint arthritis [20, 24]. The TMJ mechanical hypernociceptive response was accompanied by neutrophil influx as demonstrated by the leukocyte cell count and MPO activity. Similarly, in zymosan rat knee joint arthritis, neutrophils contribute to acute joint hyperalgesia [37].

In a model of zymosan-induced sciatic inflammatory neuritis, both low and high doses of zymosan produce territorial hypernociception. However, only the higher zymosan dose is associated with an increased release of interleukin-1, tumor necrosis factor, and reactive oxygen species from perisciatic immune cells [38]. These data support the argument that low doses of zymosan in the TMJ promoted hypernociception, although it was not associated with immune cell activation. In the present work, zymosan at $2 \mathrm{mg}$ was chosen instead of $0.25,0.5$, or $1 \mathrm{mg}$ because this dose was the only one able to change both the nociceptive behavior and the inflammatory parameters. Furthermore, considering that the hypernociception was maximal during the 4 th $\mathrm{h}$ of arthritis but the cellular influx peaked during the 6 th $\mathrm{h}$, we used these time points to assess the mechanisms underlying TMJ inflammation and the potential tools for therapy.

Regarding the inflammatory parameters, the histological features correlated to the increase in leukocyte influx, high MPO activity, and Evans blue dye extravasation, which showed an acute inflammation in the synovial membrane, the periarticular tissue, and the musculoskeletal tissue, with a predominance of neutrophils in the inflammatory cell infiltrate. Edema and a thickness in the synovial membrane were also observed. Other studies have evaluated TMJ histopathology [3, 35, 39, 40]; however, ours is the first study to describe the histopathological inflammatory parameters involving the articular and periarticular tissues in an experimental TMJ arthritis.

A large number of inflammatory and signaling substances have been suggested to play a role in joint inflammatory disorders. Among these, NO, a free oxygen radical from the L-arginine: $\mathrm{NO}$ system, is an important factor in immunological, inflammatory, and nociceptive processes, although its participation is still controversial in the inflammatory process [21]. Endogenous NO is analgesic, whereas exogenously administered NO provokes pain [41, 42]. More recently, it was shown that the NO donor 3morpholinosydnonimine (SIN-1) produces either analgesia or nociception in rats, depending on the dose and the pain model used [43]. In the zymosan arthritis model in the rat knee joints, our group has demonstrated previously that NO donors, SIN-1 and sodium nitroprusside, display analgesia in ongoing pain, revealing an intrinsic antinociceptive activity [44].

Within inflamed joints, a plethora of cells are potential sources of NO, including synoviocytes, chondrocytes, and mast cells, as well as infiltrating neutrophils and monocytes [37]. In the present study, increased nitrite/nitrate levels, an index of NO formation, were detected in the arthritic TMJ exudates. Also, histopathological analyses of immunohistochemical stains showed an increase in iNOS expression in the articular disc and articular cartilage chondrocytes and the synovial cells of zymosan arthritic TMJ. Similarly, iNOS is observed in the TMJ synovial membrane in cases of internal derangement and TMJ arthritis [22] and the activation of iNOS is evidently important in inflammatory arthritis [24].

Our results revealed that iNOS was present in the articular disc, the articular cartilage chondrocytes, and the synovial cells of the rat TMJ under physiological conditions. Immunoelectron microscopy has revealed that immunoreactive iNOS is found in both synoviocytes type A (macrophagelike) and B (fibroblast-like) [45]. NO may play an important role in the physiological maintenance of the TMJ.

In the present study, NOS inhibitors, L-NAME and $1400 \mathrm{~W}$, demonstrated anti-inflammatory effects associated with a reduction of mechanical hypernociception. NOS inhibition was associated with a significant decrease in leukocyte influx, MPO activity, and plasma extravasation in TMJ exudates. In accordance with these data, histopathological changes were mainly observed as a significant reduction of edema, cellular influx, and synovial hyperplasia. Our group has previously demonstrated that the use of both nonselective and selective iNOS inhibitors causes a general anti-inflammatory effect in zymosan-induced arthritis in the rat knee joint [24]. In the carrageenan TMJ arthritis model, neuronal nitric oxide synthase (nNOS) immunoreactivity and mRNA expression are stable during arthritis evolution, but its activity significantly increases during the chronic phases, supporting an antinociceptive role of nNOS as evidenced by pain threshold experiments [23]. 


\section{Conclusion}

In the present study, we demonstrated that a 2-mg injection of zymosan into the rat TMJ was a very robust experimental model for the study of TMJ disorders, which are often associated with spontaneous pain and subsequent effects, such as secondary hyperalgesia, allodynia, and referred pain. We showed that our animal model resulted in an inflammatory response, which was characterized by leukocyte infiltration, increased plasma extravasation and NO levels, iNOS TMJ tissue expression, and mechanical hypernociception. In this model, even if the parameters studied are normal or reduced by drug interactions, the TMJ pain can be measured non-invasively. In this regard, the administration of both nonselective and selective iNOS inhibitors was antinociceptive and anti-inflammatory in TMJ zymosan arthritis. The involvement of multiple mechanisms related to painful process associated with TMJ arthritis is indicative of the need for further investigations that may lead to the design of therapeutic alternatives for the treatment of inflammatory arthropathies.

\section{Acknowledgments}

This work was supported by Conselho Nacional de Desenvolvimento Científico e Tecnológico-CNPq, Brazil. The authors thank Maria Silvandira Franca Pinheiro and José Ivan Rodrigues de Sousa for their technical assistance.

\section{References}

[1] B. E. Cairns, "Pathophysiology of TMD pain—basic mechanisms and their implications for pharmacotherapy," Journal of Oral Rehabilitation, vol. 37, no. 6, pp. 391-410, 2010.

[2] J. G. Broton and B. J. Sessle, "Reflex excitation of masticatory muscles induced by algesic chemicals applied to the temporomandibular joint of the cat," Archives of Oral Biology, vol. 33, no. 10, pp. 741-747, 1988.

[3] D. A. Haas, O. Nakanishi, R. E. MacMillan, R. C. Jordan, and J. W. Hu, "Development of an orofacial model of acute inflammation in the rat," Archives of Oral Biology, vol. 37, no. 5, pp. 417-422, 1992.

[4] X. M. Yu, B. J. Sessle, H. Vernon, and J. W. Hu, "Effects of inflammatory irritant application to the rat temporomandibular joint on jaw and neck muscle activity," Pain, vol. 60, no. 2, pp. 143-149, 1995.

[5] J. Carleson, P. Alstergren, A. Appelgren et al., "A model for experimental induction of acute temporomandibular joint inflammation in rats: effects of substance $\mathrm{P}(\mathrm{SP})$ on neuropeptide-like immunoreactivity," Life Sciences, vol. 59, no. 15, pp. 1193-1201, 1996.

[6] J. Carleson, P. Alstergren, A. Appelgren et al., "Effects of adjuvant on neuropeptide-like immunoreactivity in experimentally induced temporomandibular arthritis in rats," Archives of Oral Biology, vol. 41, no. 7, pp. 705-712, 1996.

[7] J. Carleson, P. Alstergren, A. Appelgren et al., "A model for the study of experimentally induced temporomandibular arthritis in rats: the effect of human recombinant interleukin- $1 \alpha$ on neuropeptide-like immunoreactivity," Journal of Orofacial Pain, vol. 10, no. 1, pp. 9-14, 1996.
[8] Y. Kowai, E. Kubota, and E. Okabe, "Reactive oxygen species participation in experimentally induced arthritis of the temporomandibular joint in rats," Journal of Dental Research, vol. 79, no. 7, pp. 1489-1495, 2000.

[9] P. M. Fiorentino, B. E. Cairns, and J. W. Hu, "Development of inflammation after application of mustard oil or glutamate to the rat temporomandibular joint," Archives of Oral Biology, vol. 44, no. 1, pp. 27-32, 1999.

[10] K. Tominaga, P. Alstergren, H. Kurita, and S. Kopp, "Clinical course of an antigen-induced arthritis model in the rabbit temporomandibular joint," Journal of Oral Pathology and Medicine, vol. 28, no. 6, pp. 268-273, 1999.

[11] K. Ren, "An improved method for assessing mechanical allodynia in the rat," Physiology and Behavior, vol. 67, no. 5, pp. 711-716, 1999.

[12] R. P. Harper, C. A. Kerins, R. Talwar et al., "Meal pattern analysis in response to temporomandibular joint inflammation in the rat," Journal of Dental Research, vol. 79, no. 9, pp. 1704$1711,2000$.

[13] R. C. Roveroni, C. A. Parada, M. Cecília, F. A. Veiga, and C. H. Tambeli, "Development of a behavioral model of TMJ pain in rats: the TMJ formalin test," Pain, vol. 94, no. 2, pp. 185-191, 2001.

[14] M. L. Tang, D. A. Haas, and J. W. Hu, "Capsaicin-induced joint inflammation is not blocked by local anesthesia," Anesthesia Progress, vol. 51, no. 1, pp. 2-9, 2004.

[15] T. Lundeberg, P. Alstergren, A. Appelgren et al., "A model for experimentally induced temperomandibular joint arthritis in rats: effects of carrageenan on neuropeptide-like immunoreactivity," Neuropeptides, vol. 30, no. 1, pp. 37-41, 1996.

[16] Y. Takeuchi, J. L. Zeredo, R. Fujiyama, T. Amagasa, and K. Toda, "Effects of experimentally induced inflammation on temporomandibular joint nociceptors in rats," Neuroscience Letters, vol. 354, no. 2, pp. 172-174, 2004.

[17] A. Denadai-Souza, L. D. L. Camargo, M. T. C. P. Ribela, J. E. Keeble, S. K. P. Costa, and M. N. Muscará, "Participation of peripheral tachykinin NK receptors in the carrageenaninduced inflammation of the rat temporomandibular joint," European Journal of Pain, vol. 13, no. 8, pp. 812-819, 2009.

[18] E. C. Keystone, H. U. Schorlemmer, C. Pope, and A. C. Allison, "Zymosan-induced arthritis: a model of chronic proliferative arthritis following activation of the alternative pathway of complement," Arthritis and Rheumatism, vol. 20, no. 7, pp. 1396-1401, 1977.

[19] P. Gegout, P. Gillet, D. Chevrier, C. Guingamp, B. Terlain, and P. Netter, "Charactertzation of zymosan-induced arthritis in the rat: effects on joint inflammation and cartilage metabolism," Life Sciences, vol. 55, no. 17, pp. 321-326, 1994.

[20] F. A. C. Rocha, A. G. M. Aragao Jr., R. C. Oliveira, M. M. L. Pompeu, M. R. Vale, and R. A. Ribeiro, "Periarthritis promotes gait disturbance in zymosan-induced arthritis in rats," Inflammation Research, vol. 48, no. 9, pp. 485-490, 1999.

[21] S. Moncada, R. M. J. Palmer, and E. A. Higgs, "Nitric oxide: physiology, pathophysiology, and pharmacology," Pharmacological Reviews, vol. 43, no. 2, pp. 109-142, 1991.

[22] H. Homma, T. Takahashi, H. Seki, M. Ohtani, T. Kondoh, and M. Fukuda, "Immunohistochemical localization of inducible nitric oxide synthase in synovial tissue of human temporomandibular joints with internal derangement," Archives of Oral Biology, vol. 46, no. 1, pp. 93-97, 2001.

[23] S. A. Tesser-Viscaíno, A. Denadai-Souza, S. A. Teixeira et al., "Putative antinociceptive action of nitric oxide in the caudal part of the spinal trigeminal nucleus during chronic 
carrageenan-induced arthritis in the rat temporomandibular joint," Brain Research, vol. 1302, pp. 85-96, 2009.

[24] M. M. Bezerra, S. D. Brain, S. Greenacre et al., "Reactive nitrogen species scavenging, rather than nitric oxide inhibition, protects from articular cartilage damage in rat zymosaninduced arthritis," British Journal of Pharmacology, vol. 141, no. 1, pp. 172-182, 2004.

[25] S. M. Wahl, N. McCartney-Francis, J. Chan, R. Dionne, L. Ta, and J. M. Orenstein, "Nitric oxide in experimental joint inflammation: benefit or detriment?" Cells Tissues Organs, vol. 174, no. 1-2, pp. 26-33, 2003.

[26] C. L. Kwan, J. W. Hu, and B. J. Sessle, "Neuroplastic effects of neonatal capsaicin on neurons in adult rat trigeminal nucleus principalis and subnucleus oralis," Journal of Neurophysiology, vol. 75, no. 1, pp. 298-310, 1996.

[27] P. P. Bradley, R. D. Christensen, and G. Rothstein, "Cellular and extracellular myeloperoxidase in pyogenic inflammation," Blood, vol. 60, no. 3, pp. 618-622, 1982.

[28] G. Vaudo, S. Marchesi, R. Gerli et al., "Endothelial dysfunction in young patients with rheumatoid arthritis and low disease activity," Annals of the Rheumatic Diseases, vol. 63, no. 1, pp. 31-35, 2004.

[29] D. M. Yaillen, P. A. Shapiro, E. S. Luschei, and G. R. Feldman, "Temporomandibular joint meniscectomy: effects of joint structure and masticatory function in Macaca fascicularis," Journal of Maxillofacial Surgery, vol. 7, no. 4, pp. 255-264, 1979.

[30] E. Helmy, R. Bays, and M. Sharawy, "Osteoarthrosis of the temporomandibular joint following experimental disc perforation in Macaca fascicularis," Journal of Oral and Maxillofacial Surgery, vol. 46, no. 11, pp. 979-990, 1988.

[31] J. I. Ishimaru and A. N. Goss, "A model for osteoarthritis of the temporomandibular joint," Journal of Oral and Maxillofacial Surgery, vol. 50, no. 11, pp. 1191-1195, 1992.

[32] C. Lekkas, "Experimental degenerative temporomandibular joint disease," International Journal of Oral and Maxillofacial Surgery, vol. 23, no. 6, pp. 423-424, 1994.

[33] H. Imai, I. Sakamoto, T. Yoda, and Y. Yamashita, "A model for internal derangement and osteoarthritis of the temporomandibular joint with experimental traction of the mandibular ramus in rabbit," Oral Diseases, vol. 7, no. 3, pp. 185-191, 2001.

[34] A. F. Al-Mobireek, A. M. G. Darwazeh, and M. B. Hassanin, "Experimental induction of rheumatoid arthritis in temporomandibular joint of the guinea pig: a clinical and radiographic study," Dentomaxillofacial Radiology, vol. 29, no. 5, pp. 286 290, 2000.

[35] T. Zamma, "Adjuvant-induced arthritis in the temporomandibular joint of rats," Infection and Immunity, vol. 39, no. 3, pp. 1291-1299, 1983.

[36] K. Gado and G. Gigler, "Zymosan inflammation: a new method suitable for evaluating new antiinflammatory drugs," Agents and Actions, vol. 32, no. 1-2, pp. 119-121, 1991.

[37] M. M. Bezerra, S. D. Brain, V. C. C. Girão, S. Greenacre, J. Keeble, and F. A. C. Rocha, "Neutrophils-derived peroxynitrite contributes to acute hyperalgesia and cell influx in zymosan arthritis," Naunyn-Schmiedeberg's Archives of Pharmacology, vol. 374, no. 4, pp. 265-273, 2007.

[38] L. S. Gazda, E. D. Milligan, M. K. Hansen et al., "Sciatic inflammatory neuritis (SIN): behavioral allodynia is paralleled by peri-sciatic proinflammatory cytokine and superoxide production," Journal of the Peripheral Nervous System, vol. 6, no. 3, pp. 111-129, 2001.
[39] A. C. Goulart, F. A. Correia, S. C. Sousa, and J. G. Luz, "Study of the inflammatory process induced by injection of carrageenan or formalin in the rat temporomandibular joint," Pesquisa Odontológica Brasileira, vol. 19, no. 2, pp. 99-105, 2005.

[40] S. Fujita and K. Hoshino, "Histochemical and immunohistochemical studies on the articular disk of the temporomandibular joint in rats," Acta Anatomica, vol. 134, no. 1, pp. 26-30, 1989.

[41] S. H. Ferreira, I. D. G. Duarte, and B. B. Lorenzetti, "The molecular mechanism of action of peripheral morphine analgesia: stimulation of the cGMP system via nitric oxide release," European Journal of Pharmacology, vol. 201, no. 1, pp. 121-122, 1991.

[42] H. Holthusen and J. O. Arndt, "Nitric oxide evokes pain in humans on intracutaneous injection," Neuroscience Letters, vol. 165, no. 1-2, pp. 71-74, 1994.

[43] A. M. Sousa and W. A. Prado, "The dual effect of a nitric oxide donor in nociception," Brain Research, vol. 897, no. 1-2, pp. 9-19, 2001.

[44] J. C. D. S. Rocha, M. E. B. Peixoto, S. Jancar, F. D. Q. Cunha, R. D. A. Ribeiro, and F. A. C. Da Rocha, "Dual effect of nitric oxide in articular inflammatory pain in zymosan-induced arthritis in rats," British Journal of Pharmacology, vol. 136, no. 4, pp. 588-596, 2002.

[45] K. F. Masuda, T. Yamaza, Y. Tsukiyama et al., "Distribution of inducible nitric oxide synthase, interleukin- $1 \beta$, and interleukin-1 receptor in the temporomandibular joint of normal rats," Acta Histochemica et Cytochemica, vol. 35, no. 1, pp. 11-21, 2002. 


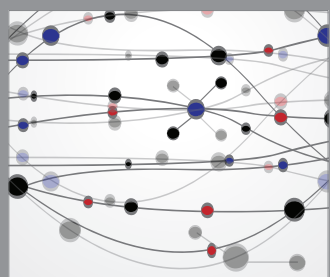

The Scientific World Journal
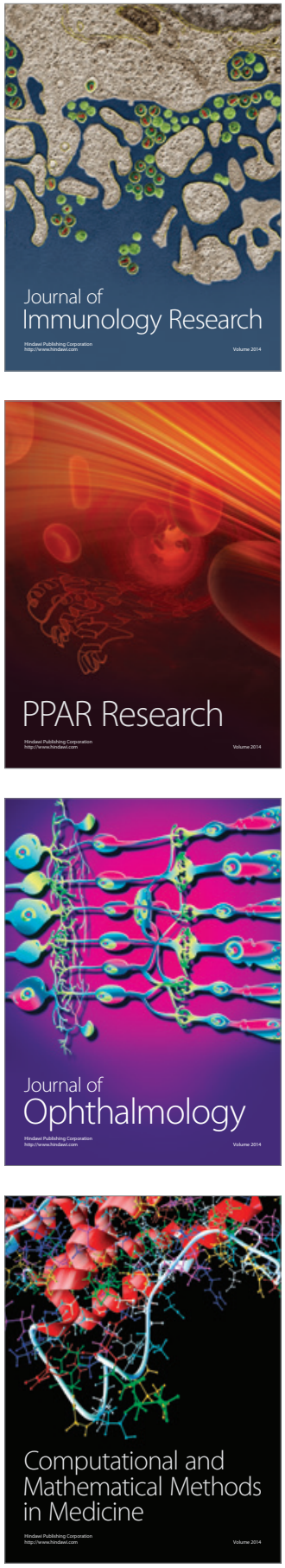

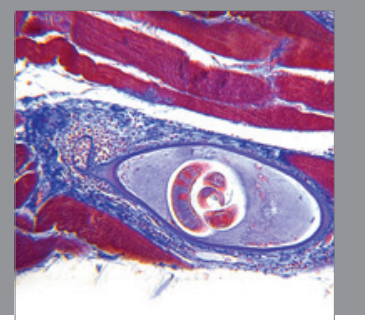

Gastroenterology

Research and Practice
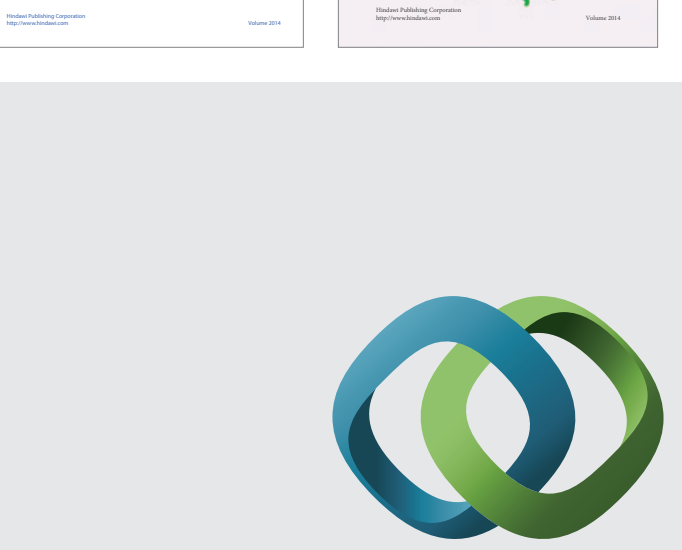

\section{Hindawi}

Submit your manuscripts at

http://www.hindawi.com
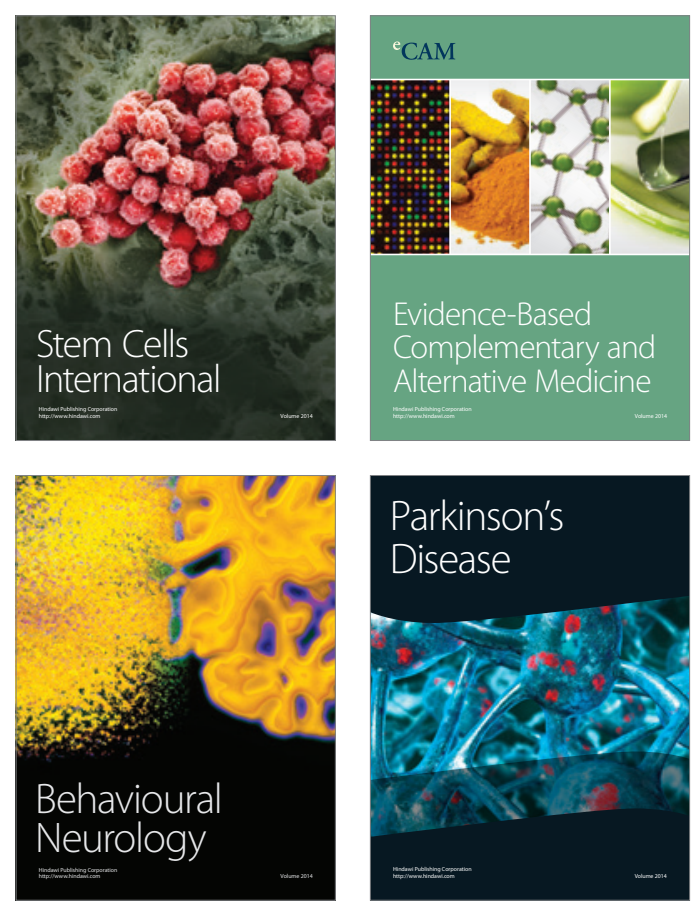

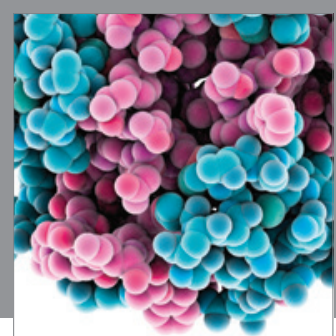

Journal of
Diabetes Research

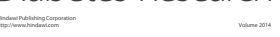

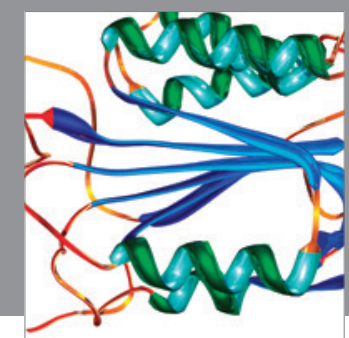

Disease Markers
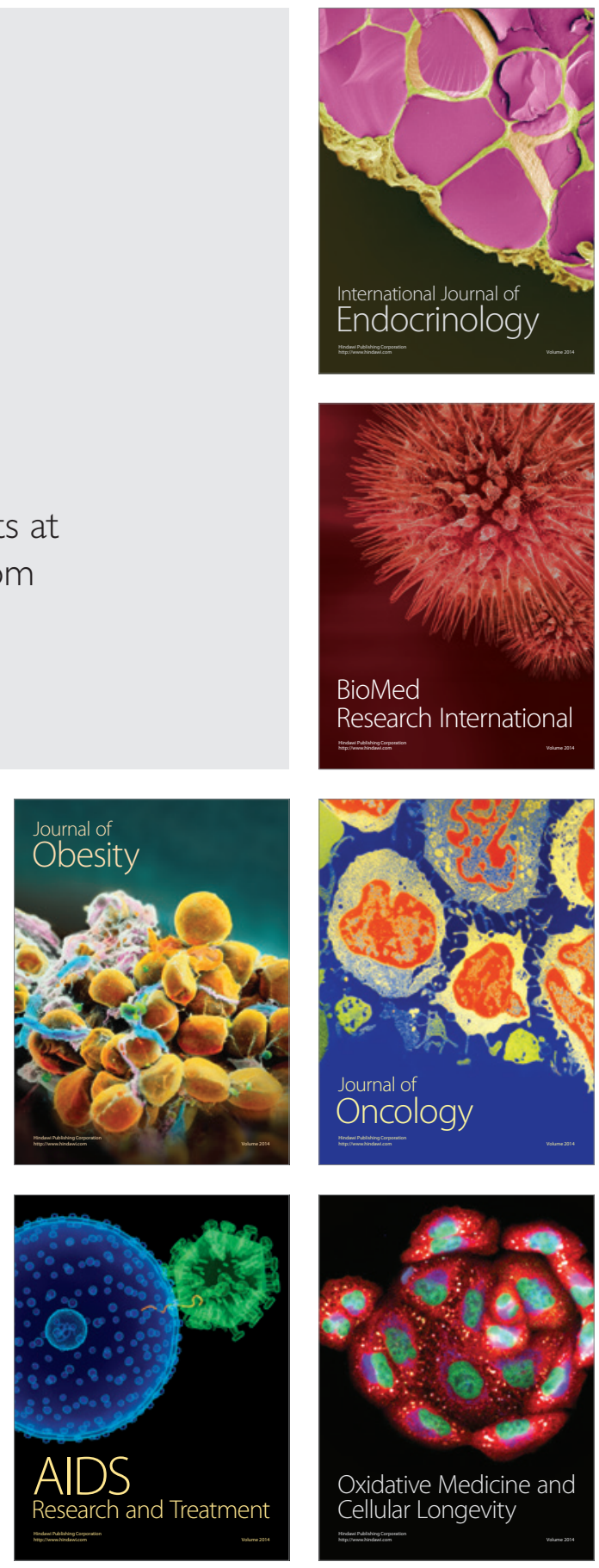